\title{
Assessment of Dowel Bars Performance in Concrete Pavement Containing Crumb Rubber of Tires
}

\author{
Muhaned G. Al-Khuzaie ${ }^{a^{*}}$, Basim H. Al-Humeidawi ${ }^{b}$, Ra'id F. Al-Sa'idi $^{c}$ \\ ${ }^{a}$ Highways and Transportation Department, College of Engineering, Mustansiriyah University, Baghdad province, Iraq \\ ${ }^{b}$ Roads and Transport Department, College of Engineering, University of Al-Qadisiyah, Al-Diwaniyah province, Iraq \\ ${ }^{c}$ Civil engineering department, College of Engineering, Mustansiriyah University, Baghdad province, Iraq
}

\section{ARTICLE INFO}

\section{Article history:}

Received 19 September 2019

Received in revised form 20 November 2019

Accepted 26 November 2019

\section{Keywords:}

Steel dowel bars

Concrete pavement

Crumb rubber

Pullout test

Joints

\begin{abstract}
A B S T R A C T
Solid waste management is one of the big challenges facing most countries around the world. Reusing these wastes in construction project represent one of the most efficient ways to consume these wastes and reduces the demand on natural sources. The Crumb Rubber (CR) of tires is a source of a huge amount of solid waste that can be reused in construction projects such as paving of roads. The current research presents an experimental investigation for the dowel bars performance in rubberized concrete pavement. The research involves conducted pullout tests for dowel bars cast in concrete pavement contains a different percentage of CR particle $(2 \%, 4 \%$, and $6 \%$ of total aggregate) as partial or total replacement to aggregate on sieves No. 16 and No. 50. Four cases of dowel bars surface were investigated. The results of the study showed that adding $\mathrm{CR}$ particles to concrete can significantly reduce the bond between the dowel bars and surrounding concrete pavement which allows for more free movement of dowel bars and reduce joint lockup. The use of treated $\mathrm{CR}$ by $\mathrm{NaOH}$ solution with standard dowel bars (epoxy coated lubricant steel dowels) can give a superior reduction in pullout load. The reductions were $45 \%, 66 \%$, and $83 \%$ in pullout load for the percentages of $2 \%, 4 \%$, and $6 \%$ crumb rubber respectively compared with the reference mix.
\end{abstract}

(C) 2019 University of Al-Qadisiyah. All rights reserved

\section{Introduction}

Cement concrete pavement is one of the largely used pavement in most counties of the word during the last century and up to now. The concrete pavement is built as series of neighboring slabs separated by joints or cracks. These joints are usually classifying to longitudinal and transverse joints according to the direction of construction. The joints are mainly responsible for releasing the stresses developed at the slabs and control the initiation of cracks[1]. The traffic loads are distributed between the adjacent slabs using aggregate interlock or dowel bars. Since the aggregate interlock is active for the very narrow cracks of less than $1 \mathrm{~mm}$, the dowel bars are the main mechanism used to transfer the load between the adjacent slabs [1-3].

The proper use of dowel bars in transverse joints of concrete pavement can significantly reduce the distress of concrete pavement. These stresses involve joint lockup, faulting, pumping, and mid-span cracks [4]. Therefore, proper design and construction of these dowels mean better load transfer across these joints and less distresses. As a result, the dowel bars can be considered as a very important part of concrete due to its role in pavement structure.

* Corresponding author.

E-mail address: mohaned.ganem26@gmail.com (Muhaned G. Al-Khuzaie) 
The rounded smooth steel dowels are the most convenient devices that used in transferring traffic loads across the transverse joints of rigid pavements especially when the pavement carries heavy traffic load and that joint opening is greater than $1 \mathrm{~mm}$ [5]. Dowel bars are usually coated with corrosion resistant material and painted with smooth lubricant (or covered with plastic sleeve) to reduce bond with surrounding concrete in order to function properly.

Many studies have been carried out in the past to evaluate the performance of dowel bars across the transfer joints of the concrete pavement [6-9]. Most of these studies were focused on the most identification of the problems with the performance of the steel dowel bars and trying to overcome these problems. Other studies were investigated different alternative materials either to overcome the corrosion problem and related joint lockup or to upgrade dowel bars performance and consequently allows for free movement of slabs during expansion and contraction and prevent joint lockup [10-12]. The elliptical dowels and GFRP dowels are used in rigid pavement to determine whether they are a viable alternative to round steel dowels in highway joints [11]. The results of this study show that elliptically shaped dowels reduce bearing stresses at the dowelconcrete interface. The study also shows that GFRP dowels have load transfer capacities nearly as large as the steel and stainless-steel dowels studied. However, the deflections measured for the elliptical dowels and GFRP dowels were greater than those for round steel dowels. Another study evaluates fiber reinforced polymer (FRP) dowel bars as load transferring devices in jointed plain concrete pavement (JPCP) under HS25 static and fatigue loads and compares their response with JPCP consisting of steel dowels [12]. They found good results for (FRP) in maximum bending deflection, relative deflection (RD), and bearing stress of dowels in addition to its long-term performance. Another study focused on the evaluation of the load-deflection response of GFRP dowels using a scaled model of pavement slabs showed that the $38 \mathrm{~mm}$ GFRP dowels perform better in terms of deflection response compared to the $25 \mathrm{~mm}$ steel dowels [13]. Also, it was observed that the relative deflection (RD) is more sensitive to the changes in the joint width rather than the concrete strength.

Most of these studies were dealing with preventing or reducing joint lockup by changing the dowel bars material. The current research focused on adding Crumb Rubber (CR) particles to the concrete pavement as a partial replacement for fine aggregate to reduce the bond between the dowel bars and surrounding concrete and reduce or prevent joint lockup. This was achieved by conducting pullout test for dowel bars cast in rubberized concrete pavement.

\section{Test methodology}

The test included pulling-out one aligned dowel bar from a concrete block to assess the dowel-concrete interaction in the presence of crumb tire rubber within the concrete. The concrete block was cast with dimensions of $(200 \times 200 \times 350) \mathrm{mm}$, while the steel dowel dimensions were $25 \mathrm{~mm}$ for the diameter and $458 \mathrm{~mm}$ for the length with half of it embedded in concrete as recommended by AASHTO 1993 Guideline [2]. Four cases of dowel bars surface were examined as uncoated un-lubricant dowel, uncoated lubricant dowel, epoxy-coated un-lubricant dowel, and epoxy-coated lubricant dowel.

\section{Materials \\ 3.1. Concrete}

The concrete mix design was carried out according to ACI 2002 [14] to satisfy the requirement of concrete compressive strength of rigid pavement (30 Mpa for cube) as per SCRB [15]. All the variables that have been adopted in the design of concrete mix were determined laboratory. The slump for rigid pavement according to ACI code 211.91 [16] ranging from (2.5 -7.5) $\mathrm{cm}$ and according to SCRB [15] from (0-5) cm, in the design of concrete mix, it was taken as $5 \mathrm{~cm}$. The slump concrete was tested according to ASTM C143/C143M [17] for all cases of rubberized concrete mixes. The results of mix design for $1 \mathrm{~m}^{3}$ are found in the Table (1).

Table 1 - Concrete mix proportions

\begin{tabular}{ll}
\hline Materials & Weight in $\mathbf{~ g}$ \\
\hline Water & 193 \\
Cement & 395 \\
Gravel & 1149 \\
Sand & 792 \\
\hline
\end{tabular}

\subsection{Epoxy coated steel Dowel Bars}

Dowel bars used in this study were manufactured from mild steel grade 60 with minimum tensile strength of $90 \mathrm{Mpa}$ and minimum yield strength of $60 \mathrm{Mpa}$ as recommended by ASTM A615 / A615M - 09[18]. To ensure that the tensile strength is satisfied with the minimum requirement mentioned in the above standard, a test of tensile strength of the dowel bar was done according to ASTM A615 / A615M - 09. The obtained tensile strength was $235.5 \mathrm{Mpa}$ and the yield strength was $150 \mathrm{Mpa}$ which are more than the required tensile and yield strengths. Figure (2) shows the stressstrain relationship of the steel dowel bar.

The epoxy coating used in this research was sikagard - 62 which is a twopart epoxy protective coating $\mathrm{A}$ and $\mathrm{B}$. The mixing ratio between the two parts is 3.75 from A to 1.25 from B (3.75: 1.25$)$ as recommended by its datasheet. The epoxy was manufactured to satisfy British standard BS 6920 [19]. Many researchers coated the dowel bars manually, however, that may produce not smooth surface and not equal thickness for all dowel but it can provide adequate corrosion resistance for dowel bars. The epoxy properties obtained from Sika Company as shown in the Table (2). Figure (1) shows the steel dowel bar after coating with epoxy.

Table 2 - Properties of epoxy coating.

\begin{tabular}{lcl}
\hline Property & Magnitude & Property \\
\hline Density & $1.35 \pm 0.05 \mathrm{~kg} / \mathrm{l}$ & Density \\
Thermal Expansion Coefficient $(\alpha) 7.5 \times 10^{\wedge}(-5)$ & Thermal Expansion \\
& {$\left[\alpha=\mathrm{m} / \mathrm{m} /{ }^{\circ} \mathrm{C}\right]$} & Coefficient $(\alpha)$ \\
Bond Strength with concrete & $3.5 \mathrm{~N} / \mathrm{mm}^{2}$ & Bond Strength \\
\hline
\end{tabular}

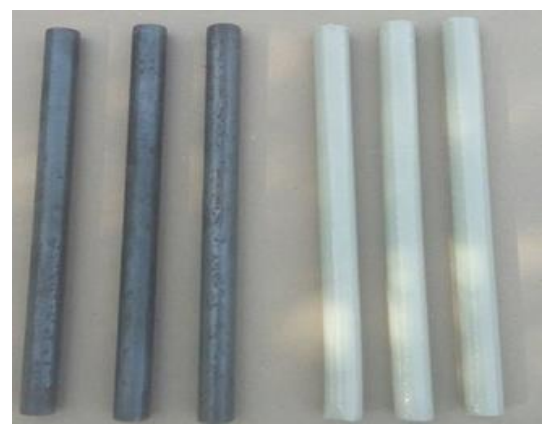

Fig. 1 - Coated and uncoated steel dowel bars 
Dowel bar should be covered with a light layer of grease or oil to prevent or reduce bonding between dowel and the surrounding concrete as recommended in AASHTO [2]. In this research, the light oil SAE 10 was used to lubricant the dowel bar, since covering dowel bars with grease may cause looseness (gap) in the surrounding concrete of dowel bar which consequently reduces transferring of load and cause joint failure.

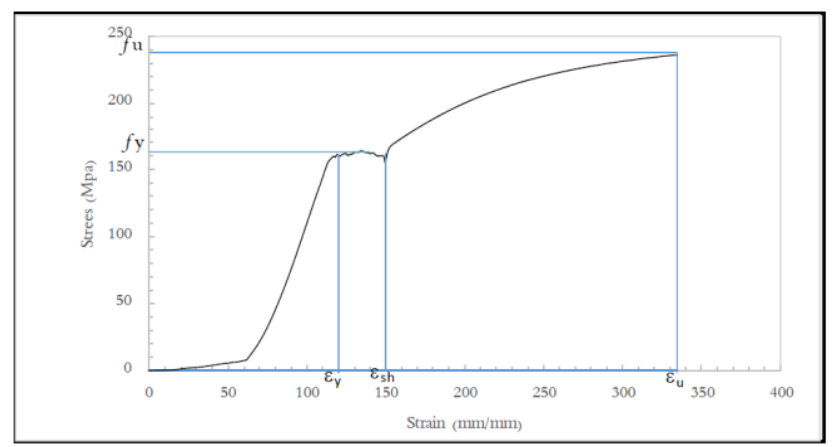

Fig. 2 - Stress-strain relationship of steel dowel bar

\subsection{Crumb Rubber}

The CR that used in the research was obtained from Babylon tires factory in Iraq. Three sizes of CR particles were used in experimental work, which was retained on the sieve No.16 $(1.18 \mathrm{~mm})$, No.50 $(0.3 \mathrm{~mm})$, and sieve No.100 $(0.15 \mathrm{~mm})$ as shown in figure (3). According to a previous study by the authors, the replacement was conducted for particles retained on sieve No. 16 and No.50. The physical and chemical properties of CR are presented in Table (3) as obtained from Babylon tires factory.

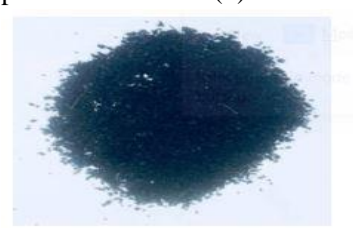

(a)

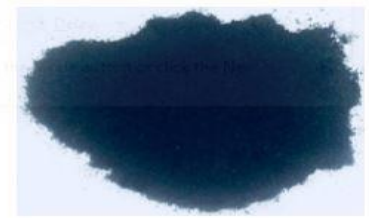

(b)

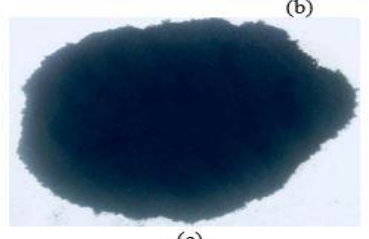

(c)

Fig. 1 - Crumb rubber particles: (a) retained on sieve No. 16, (b) retained on sieve No. 50, (c) retained on sieve No. 100

Table 3 -chemical and physical properties of crumb rubber

\begin{tabular}{|c|c|c|c|}
\hline \multirow{2}{*}{$\begin{array}{l}\text { Chemical composition } \\
\text { Rubber hydrocarbon }\end{array}$} & \multicolumn{3}{|c|}{ Physical properties } \\
\hline & Cont & Physical properties & Test result \\
\hline $\begin{array}{lll}\begin{array}{l}\text { Rubber } \\
\text { (SBR) }\end{array} & \text { hydro } & \text { carbor }\end{array}$ & $\mathrm{n}_{48 \%}$ & Density & $0.95 \mathrm{~g} / \mathrm{cm} 3$ \\
\hline Carbon black & $31 \%$ & Ultimate tensile strength & $9 \mathrm{MPa}$ \\
\hline Acetone extract & $15 \%$ & Elongation at break & $150 \%$ \\
\hline Ash & $2 \%$ & & \\
\hline Residue chemical balance & $4 \%$ & Hardness shore A & 64 \\
\hline
\end{tabular}

The $\mathrm{CR}$ was treated using sodium hydroxide $(\mathrm{NaOH})$. It is a Solid white composite compound and it dissolves easily in water and is an alkaline solution. The $\mathrm{NaOH}$ is also known as caustic soda because it is a very strong alkaline material, therefore, it is used in many industries and sterilization processes. Several research works that dealt with CR used $\mathrm{NaOH}$ solution to eliminate the zinc stearate. Zinc stearate is formed during the production of tires during the uses of stearic acid zinc as a lubricant, anti-adherent, and use as activating agent of vulcanization urge medium [20]. As mentioned above the chemical treatment of $\mathrm{CR}$ was done by $\mathrm{NaOH}$ solution, it's very important method for improving the adhesion between cement and crumb rubber. $\mathrm{NaOH}$ solution is the most efficient method to remove the zinc stearate (zinc salts) which appears as layers on concrete samples. These salts are composed of the crumb rubber surface during the tire manufacturing process [21]. $\mathrm{NaOH}$ solution is a strong base solution that has erosion effect because of its high alkalinity, so this solution will scratch crumb rubber surface during mixing process This process makes the surface of crumb rubber more rough and lead to significant improvement of the adhesion between cement and crumb rubber particles [22]. The concentration of $\mathrm{NaOH}$ solution used in this research was $10 \%$ and obtained by adding $100 \mathrm{gm}$ of $\mathrm{NaOH}$ particles to 1 litter of water. The treatment of $\mathrm{CR}$ involved washing the $\mathrm{CR}$ by water, then submerging the crumb rubber particles for $30 \mathrm{~min}$. in a container having $\mathrm{NaOH}$ solution. The $\mathrm{PH}$ level is raised and become alkaline base and finally washing crumb rubber particles by water until its $\mathrm{pH}$ became neutral. The washed crumb rubber then left exposed to air until it becomes dry.

\section{Results and discussion}

Dowel bars are usually coated with epoxy to protect from corrosion and helping the horizontal movement of them. This coating may knock during installing and casting which causes corrosion and premature failure. The wearing of epoxy coated may cause rougher surface even in the presence of lubricant or plastic sleeve and consequently increase the friction between dowel bar and surrounding concrete, and obstruct free movement of the slab. In this study, CR was added to the concrete mix to improve the performance of concrete and reduce the bond between dowel and concrete pavement by converting the concrete from a brittle to a relatively ductile material without affecting its mechanical properties and load transfer efficiency of dowel bar. This was carried out by investigation of the bondslip behavior of dowel bars by using pullout test technique. Four cases of dowel bars surface were also investigated as uncoated un-lubricated dowel bars, epoxy-coated un-lubricated dowel bars, uncoated lubricant dowel bars and epoxy-coated lubricant dowel bars. All results of pullout test are shown in Table (4). Figure (4) shows the pullout test sample at the testing machine. Sixteen parameters were included in the testing program as shown in the testing matrix in Table (4).

\section{Table 4 -results of pullout test $(\mathrm{kN})$}

\begin{tabular}{lllll}
\hline$\%$ replacement of CR particles & $0 \%$ & $2 \%$ & $4 \%$ & $6 \%$ \\
\hline Uncoated dowel unlubricated & 77 & 58 & 47 & 35 \\
Coated dowel & 96 & 53 & 42 & 30 \\
Uncoated lubricant & 52 & 37 & 34 & 19 \\
Coated lubricant & 29 & 16 & 10 & 5 \\
28 days compressive strength & 39 & 36 & 33 & 28 \\
\hline
\end{tabular}

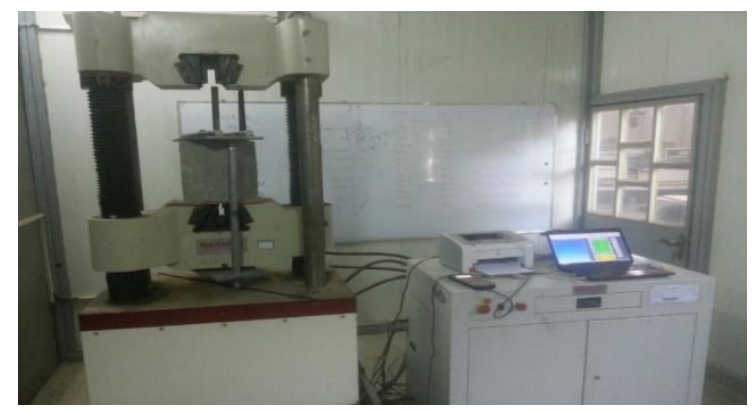

Fig. 4 - Pullout test sample at the testing machine. 


\subsection{Effect of CR content}

The general achievement which can be observed from Table (4), that the $\mathrm{CR}$ has greatly reduced the pullout value of the dowel bar and augmenting the free movement of the slab. From that table it can be observed that in case of uncoated un-lubricated dowel, the adding of $2 \% \mathrm{CR}$ particles reduces pullout value by $24.6 \%$ compared with a reference mix and when adding $4 \% \mathrm{CR}$ particles the pullout value reduces by $38.9 \%$ compared with the reference mix. This reduction significantly increased by adding $6 \% \mathrm{CR}$ particles in which the pullout load decreased by $54.5 \%$ compared with the reference mix. The reason for this decrease is the effect of CR particles which transformed the concrete from a brittle material into elastic material leading to a good separation between the dowel bar and the concrete. Figure (5) shows the bond-slip behaviour of the four cases of the uncoated unlubricated dowel bar. All values of these curves gradually decrease as the percentage of rubber increases due to the presence of this material (CR) which reduced the brittleness of the concrete.

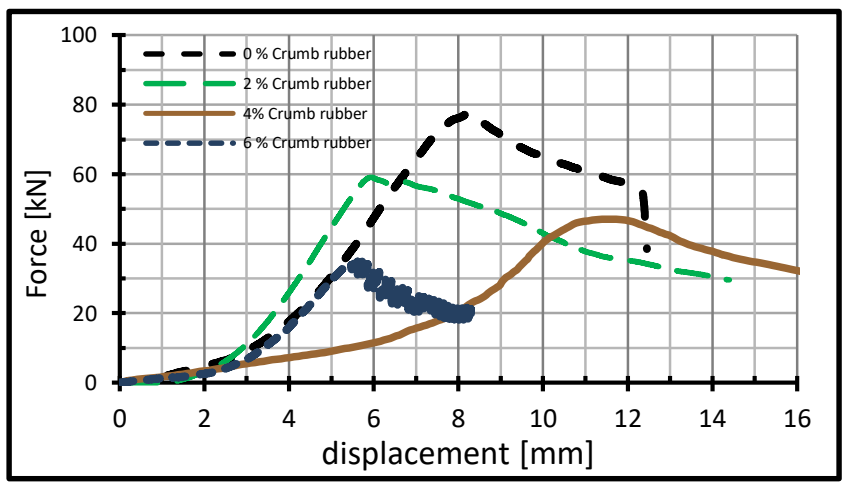

Fig. 5 - load-displacement curves for the case of uncoated unlubricated dowel bars.

\subsection{Effect of epoxy coating of dowel}

In addition to protection against corrosion the epoxy, coating can play a vital role in reducing the bond between dowel bar and concrete. The experimental results showed that the coating of the dowel bar with epoxy can reduce the bond with rubberized concrete mixes for all rubber percentages. The pullout loads decrease by $9 \%, 11 \%$, and $14 \%$ compared with that of an un-coated dowel for samples containing $2 \%, 4 \%$, and $6 \%$ CR respectively (see Table (4)). In the case of the sample which has zero percentage of crumb rubber, the results showed inconsistent behavior compared with all other samples because the epoxy may not always provide good separation between the dowel bar and the concrete [23]. This doubtful performance may be attributed to the way of dowel bars coating. The manual coating of dowel bars may affect the results due to changing coating thickness or irregularities of surface, however, the general trend can be observed from the other samples.

The epoxy coating is milling the very small holes and irregularities of the dowel bar surface so as reduce the friction between dowel bars and surrounding concrete and reduce the pullout load. Moreover, it acts as a separation layer between the dowel bar and concrete. Figure (6) shows the bond-slip behavior of the four investigated cases of epoxy coated unlubricated dowel bars. The curve for $0 \%$ does not behave like the rest of the curves because in this case there is no effect of crumb rubber unlike the rest of curves where we find the effect of crumb rubber and epoxy together.

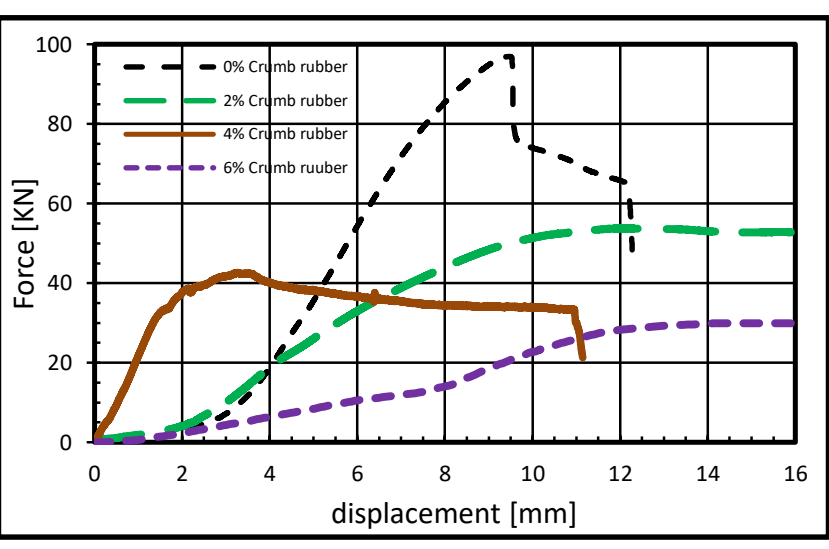

Fig. 6 - load-displacement curves for the case of coated unlubricated dowel bars for different percentages of CR.

\subsection{Effect of lubricant on uncoated dowel}

The lubricant of dowel bars is significantly reducing the pullout load. This reduction is increased by increasing the percentage of crumb rubber. The percentages of reduction are $32.5 \%, 34.5 \%, 27.6 \%$, and $46 \%$ compared with uncoated un-lubricant samples containing $0 \%, 2 \%, 4 \%$, and $6 \% \mathrm{CR}$ respectively (see Table (4)). This reduction is higher compared with the specimens containing coated dowel un-lubricant. This behavior is due to that the lubricant can generate a separation layer between the concrete and dowel, and reduce the growth of bond during the casting process.

Moreover, the coating is still necessary to protect dowel bars against corrosion and relatively decreasing the bond with concrete. Figure (7) shows the bond-slip behavior of the cases of uncoated lubricant dowel bars for different percentages of rubbers. In this figure we see values lower than figure 6, but we cannot work without the epoxy for the previous reason.

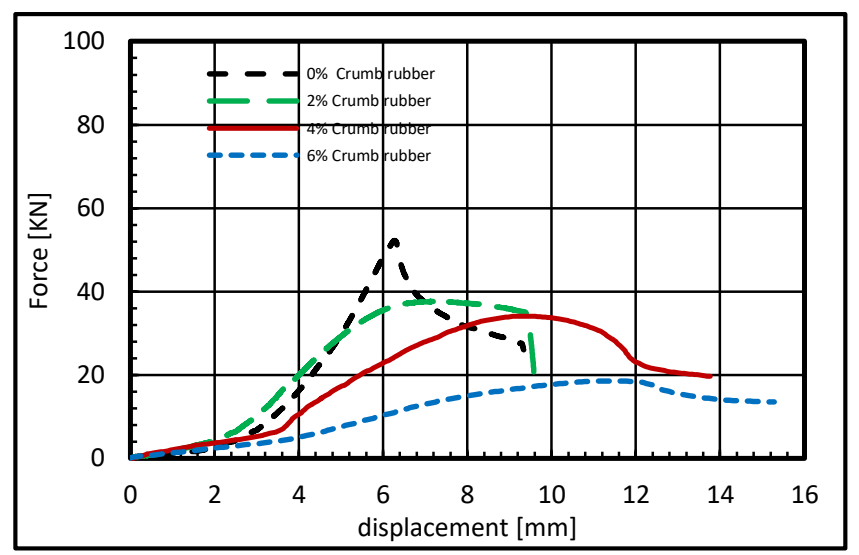

Fig. 7 - load-displacement curves for the case of uncoated lubricated dowel bars for different percentages of rubbers.

\subsection{Effect of greasing (lubricant) and coating of dowel}

The best results of the pullout test were obtained in the case of epoxycoated lubricant dowel bars as the least pullout loads were recorded. Even the use of epoxy coated lubricant dowel bars are common, the use of these dowels with rubberized concrete pavement can significantly reduce the pullout load. The pullout loads were decreased by $45 \%, 66 \%$, and $83 \%$ for 
epoxy coated lubricant dowel bars cast in concrete pavement containing $2 \%, 4 \%$, and $6 \%$ crumb rubber respectively compared with that contain $0 \%$ crumb rubber. The results revealed the using of $\mathrm{CR}$ with standard dowel bars (epoxy coated lubricant dowel) is more effective in reducing the pullout load compared with using crumb rubbers with uncoated unlubricant dowel bars, in which the reduction was $25 \%, 39 \%$ and $55 \%$ for specimens containing $2 \%, 4 \%$, and $6 \%$ CR respectively. Figure (8) shows bond-slip behaviour for the four cases of epoxy coated and lubricated dowel.

The positive response regarding to pullout load for dowel bars in rubberized concrete pavement is attributed to increase the elasticity of concrete due to adding the crumb rubber. Also, the triple effect of crumb rubber and lubrication with epoxy makes the case of epoxy-coated lubricant dowel bars is the better case of the above cases. We notice that the values of these curves are very few, which indicates that this case is the best of the previous cases.

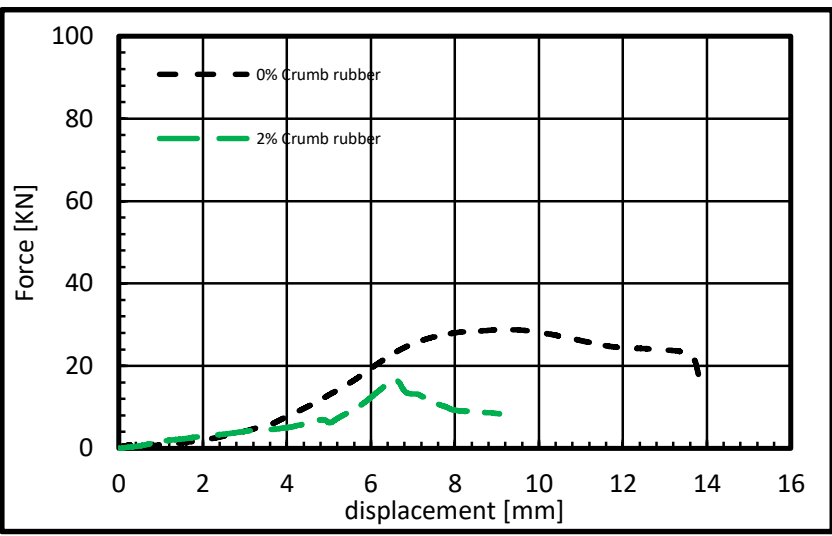

Fig. 8 - load-displacement curves for the case of coated lubricated dowel bars for different percentages of rubbers.

The visual inspection for the dowel concrete interface supports the pullout load test results. In cases of specimens containing coated lubricated dowel bars and 6\% CR, insignificant cracks were observed at the joint face as can be seen in figure (9). While for the same case of dowel surface cast in concrete has $0 \% \mathrm{CR}$, significant cracks were observed at the joint face as can be seen in figure (10).

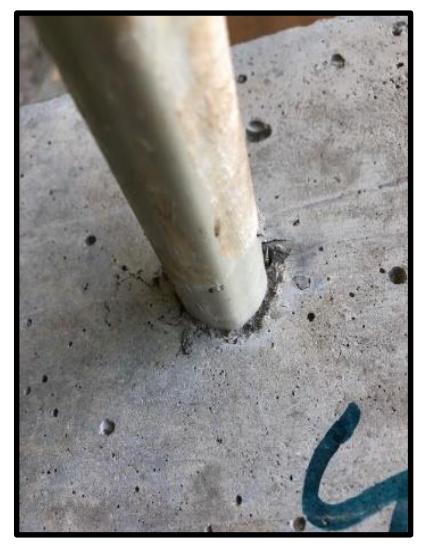

Fig. 9 - Slip of dowel bar for coated lubricated dowel bars at concrete contains $6 \% \mathrm{CR}$

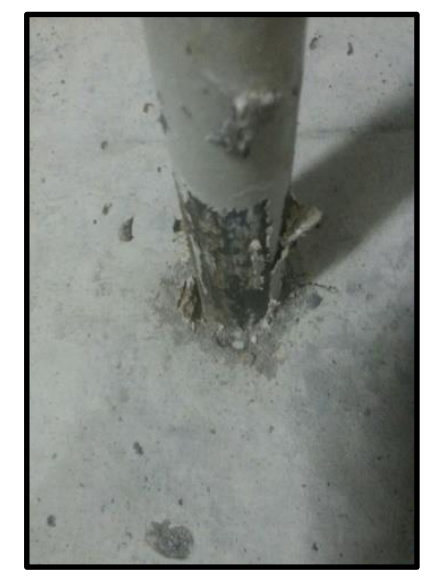

Fig. 10 - Slip of dowel bar for coated lubricated dowel bars at concrete contains $0 \%$ CR

\section{Summary and conclusions}

The using of waste plastic and recycling it, is one of the most important processes to convert the negative effect of these waste to positive point by reducing the demand on natural resources and overcome some structural problems. The dowel concrete friction is one of the main concerns of premature failure of joint and concrete pavement overall. The current study focused on using waste CR particles with different sizes to improve joint movement and reduce the required load to open the joint.

The results of the study showed that the use of crumb rubbers particles significantly reduces the pullout load and improve the joint movement and keeping acceptable strength up to using $4-6 \%$ percent of crumb rubbers particles from the total aggregate weight.

The main conclusions of this research are as follows:

1-The use of treated $\mathrm{CR}$ by $\mathrm{NaOH}$ solution with standard dowel bars (epoxy coated lubricant steel dowels) can give a superior reduction in pullout load. It produced $45 \%, 66 \%$, and $83 \%$ reduction in pullout load for the percentages of $2 \%, 4 \%$, and $6 \%$ crumb rubber respectively compared with the reference mix.

2-The using of treated $\mathrm{CR}$ by $\mathrm{NaOH}$ solution even with the case of nonstandard dowel bars (uncoated lubricated dowels) or in cases of bad preparing, installing and construction of dowel bars can improve the joint movement and reducing premature failure by reducing pullout load by 25 $\%, 39 \%$ and $55 \%$ for the percentages of $2 \%, 4 \%$ and $6 \%$ crumb rubber respectively compared with the reference mix.

\section{REFERENCES}

[1] S. Rao, K. Hoegh, T. Yu, L. Khazanovich, Evaluation of dowel alignment constructability in Portland cement concrete pavements, Transportation Research Record, 2098(1) (2009) 86-93.

[2] AASHTO, AASHTO guide for design of pavement structures, in, American Association of State Highway

Transportation Officials, Washington, D.C, 1993.

[3] B.H. Al-Humeidawi, P. Mandal, Evaluation of performance and design of GFRP dowels in jointed plain concrete pavemental part 1: experimental investigation, International Journal of Pavement Engineering, 15(5) (2014) 449-459.

[4] G. Li, M.A. Stubblefield, G. Garrick, J. Eggers, C. Abadie, B. Huang, Development of waste tire modified concrete, Cement and Concrete Research, 34(12) (2004) 2283-2289.

[5] S.R. Maitra, K.S. Reddy, L.S. Ramachandra, Load transfer characteristics of dowel bar system in jointed concrete pavement, Journal of Transportation Engineering, 135(11) (2009) 813-821.

[6] L.W. Teller, H.D. Cashell, Performance of doweled joints under repetitive loading, 
Highway Research Board Bulletin, (217) (1959).

[7] C. Channakeshava, F. Barzegar, G.Z. Voyiadjis, Nonlinear FE analysis of plain concrete pavements with doweled joints, Journal of Transportation Engineering, 119(5) (1993) 763-781

[8] N. Buch, D.G. Zollinger, Development of dowel looseness prediction model for jointed concrete pavements, Transportation Research Record, 1525(1) (1996) 2127.

[9] S.N. Shoukry, G.W. William, M.Y. Riad, Evaluation of load transfer efficiency measurement, Pennsylvania Transportation Institute, Pennsylvania State University, 2005.

[10] Y. Bian, Investigation of fiber reinforced polymer (FRP) dowel bars in rigid pavements, University of California, Davis, 2008

[11] M. Porter, N. Pierson, Laboratory evaluation of alternative dowel bars for use in Portland cement concrete pavement construction, Transportation Research Record, 2040(1) (2007) 80-87.

[12] P.V. Vijay, H. Li, H.V. GangaRao, Design and evaluation of jointed plain concrete pavement with fiber reinforced polymer dowels, United States. Federal Highway Administration. Office of Research and Technology Services, 2009.

[13] B.H. Al-Humeidawi, P. Mandal, Evaluation of performance and design of GFRP dowels in jointed plain concrete pavemental part 2: numerical simulation and design considerations, International Journal of Pavement Engineering, 15(8) (2014) 752-765.

[14] ACI Committee, Standard Practice for Selecting Proportions for Normal, Heavyweight, and Mass Concrete, American Concrete Institute, in: ACI code
211.91 American Concrete Institute, 2002

[15] SCRB, Standards Specifications for Roads and Bridges-R8, in, 2014

[16] ACI Committee 211, Standard Practice for Selecting Proportions for Normal, Heavyweight, and Mass Concrete - ACI 211.1-91 (Reapproved 2002), in, ACI Manual of Concrete Practice, 2004, pp. 38.

[17] ASTM C143/C143M, Standard Test Method for Slump of Hydraulic-Cement Concrete1", in, ASTM International, West Conshohocken, 2005.

[18] ASTM A615 / A615M - 09, Standard specification for deformed and plain carbon-steel bars for concrete reinforcement, in, ASTM International 2009.

[19] British Standard BS 6920-1, Suitability of non-metallic products for use in contact with water intended for human consumption with regard to their effect on the quality of the water, in, BSi Group, London, UK, 2014.

[20] N. Segre, I. Joekes, Use of tire rubber particles as addition to cement paste, Cement and concrete research, 30(9) (2000) 1421-1425.

[21] F. Pacheco-Torgal, Y. Ding, S. Jalali, Properties and durability of concrete containing polymeric wastes (tyre rubber and polyethylene terephthalate bottles): An overview, Construction and Building Materials, 30 (2012) 714-724.

[22] S. Tian, T. Zhang, Y. Li, Research on modifier and modified process for rubberparticle used in rubberized concrete for road, in: Advanced Materials Research, Trans Tech Publ, 2011, pp. 4125-4130.

[23] L. Bronuela, S. Ryu, Y.H. Cho, Cantilever and pull-out tests and corresponding FEM models of various dowel bars in airport concrete pavement, Construction and Building Materials, 83 (2015) 181-188. 